\title{
Occurrences and Behaviors of Naphthenic Acids in a Petroleum Refinery Wastewater Treatment Plant
}

\author{
Beili Wang, ${ }^{\dagger}$ Yi Wan, ${ }^{\dagger}{ }^{\dagger}$ Yingxin Gao, ${ }^{\ddagger}$ Guomao Zheng, ${ }^{\dagger}$ Min Yang, ${ }^{\ddagger}$ Song Wu, ${ }^{\S}$ and Jianying $\mathrm{Hu}^{\dagger}$ \\ ${ }^{\dagger}$ Laboratory for Earth Surface Processes, College of Urban and Environmental Sciences, Peking University, Beijing 100871, People’s \\ Republic of China \\ ${ }^{\ddagger}$ Chinese Academy of Sciences, State Key Laboratory of Environmental Aquatic Chemistry, Ecoenvironmental Science Research \\ Center, Beijing 100085, People's Republic of China \\ ${ }^{\S}$ Petrochina Ji Dong Oilfield Company, Tangshan, 063200 Hebei, People’s Republic of China
}

Supporting Information

ABSTRACT: Naphthenic acids (NAs) are one class of compounds in wastewaters from petroleum industries that are known to cause toxic effects, and their removal from oilfield wastewater is an important challenge for remediation of large volumes of petrochemical effluents. The present study investigated occurrences and behaviors of total NAs and aromatic NAs in a refinery wastewater treatment plant, located in north China, which combined physicochemical and biological processes. Concentrations of total NAs were semiquantified to be $113-392 \mu \mathrm{g} / \mathrm{L}$ in wastewater from all the treatment units, and the percentages of aromatic NAs in total NAs was estimated to be $2.1-8.8 \%$. The mass reduction for total NAs and aromatic NAs was $15 \pm 16 \%$ and $7.5 \pm$ $24 \%$ after the physicochemical treatment, respectively. Great mass reduction (total NAs: $65 \pm 11 \%$, aromatic NAs: $86 \pm 5 \%$ ) was observed in the biological treatment units, and antiestrogenic activities observed in wastewater from physicochemical treatment units disappeared in the effluent of the activated sludge system. The distributions of mass fractions of NAs demonstrated that biodegradation via activated sludge was the major mechanism for removing alicyclic NAs, aromatic NAs, and related toxicities in the plant, and the polycyclic NA congener classes were relatively recalcitrant to biodegradation, which is a complete contrast to the preferential adsorption of NAs with higher cyclicity (low $Z$ value). Removal efficiencies of total NAs were $73 \pm 17 \%$ in summer, which were higher than those in winter (53 $\pm 15 \%)$, and the seasonal variation was possibly due to the relatively high microbial biotransformation activities in the activated sludge system in summer (indexed by $\mathrm{O}_{3}-\mathrm{NAs} / \mathrm{NAs}$ ). The results of the investigations indicated that biotransformation of NA mixtures by the activated sludge system were largely affected by temperature, and employing an efficient adsorbent together with biodegradation processes would help cost-effectively remove NAs in petroleum effluents.

\section{INTRODUCTION}

Due to the increasing importance of petroleum for industrial development in the last decades, petrochemical effluents have had a significant impact on pollution of surface water systems. ${ }^{1}$ The amount of wastewater generated from the refining of petroleum is $0.5-1.6$-fold greater than the volume of petroleum that is refined. ${ }^{2}$ Petroleum refinery wastewater (PRWW) comprises different amounts of hazardous pollutants, of which naphthenic acids (NAs) are a class of compounds that have been reported to be toxic and persistent, especially in the oil sands process-affected water (OSPW) in northeastern Alberta, Canada. ${ }^{1,3-6}$ Degradation of NAs in wastewater from the petroleum industry is an important challenge for remediation of the large volumes of petrochemical effluents. ${ }^{7}$

Removal of NAs in wastewater treatment plants (WWTP) plays a crucial role in pollution control, and the treatment process of the PRWW generally consists of mechanical and physicochemical technologies including oil-water separation and coagulation, followed by biological treatment within the integrated activated sludge treatment plant. ${ }^{8}$ Laboratory studies have evaluated various technologies and processes for removing NAs in OSPW, such as biological treatment, ${ }^{5,9-14}$ membrane filtration, ${ }^{15-17}$ ozonation, ${ }^{18-20}$ and chemical coagulation, ${ }^{21-24}$ but much less attention has been given to treatment of PRWW. While nanofiltration could remove $>95 \%$ NAs in wastewater ${ }^{15}$ and ozonation treatment achieved approximately $50 \%$ and $75 \%$ NA degradation in lab, ${ }^{20}$ biological treatment is the most efficient and cost-effective method in refineries. ${ }^{5,9-14}$ Recently, occurrences of NAs in activated sludge wastewater from six petroleum refineries in the United States has been investigated, ${ }^{25}$ but the fates of NAs remain unknown and there is still

Received: November 18, 2014

Revised: $\quad$ March 25, 2015

Accepted: April 7, 2015

Published: April 7, 2015 
a lack of understanding as to which processes in the WWTP are affecting the removal of NAs. It is well-known that use of mass balance analysis to understand behaviors of pollutants in WWTP can be useful for identification of mechanisms that are best suited for removal of pollutants and that assessment of efficiencies of different treatment units of a WWTP for removal of NAs could provide information needed to improve performance of these plants. However, little is known about the fate and major mechanisms for the removal of NAs in fullscale WWTPs.

Beside alicyclic "classical" NAs, aromatic NAs were recently identified by comprehensive two-dimensional gas chromatography - mass spectrometry $(\mathrm{GC} \times \mathrm{GC}-\mathrm{MS})$ of the methyl esters in OSPW. ${ }^{26-28}$ Although aromatic NAs make up a small percentage of NA mixtures $(<10 \%$ in crude oils), they are the most environmentally significant components of the overall toxicity and recalcitrance of NAs found in wastewaters from the petroleum industry. ${ }^{29,30}$ For example, the aromatic NAs with chemical formulas similar to estrone- and estradiol-like compounds have been demonstrated to cause estrogenicity in fish larvae. ${ }^{31,32}$ Several biodegradation studies reported the microorganisms and mechanisms involved in degradation of individual aromatic NA compounds; ${ }^{30,33}$ however, there is very little understanding of aromatic NAs in water and solid fractions during physiochemical treatment and activated sludge treatment processes.

The present study investigated occurrences of total NAs (including both alicyclic and aromatic NAs) in aqueous and solid matrices in a petroleum refinery wastewater treatment plant, north China, and performed a mass balance of total NAs and aromatic NAs based on field measurements. The toxicities of wastewater samples from different treatment units were also measured by the yeast two-hybrid assay. The obtained field results were applied to assess the physicochemical and biological processes that may be effective for the removal of total NAs and aromatic NAs in wastewater. The seasonal variations of total NAs and their oxidized products (oxy-NAs) were further explored for clarification of the possible factors affecting the removal efficiencies.

\section{MATERIALS AND METHODS}

Sample Collection. The petroleum refinery wastewater treatment plant investigated in the present study is designed to treat $20000 \mathrm{~m}^{3} / \mathrm{d}$ wastewater generated by oil production platforms in Hebei Province, north China. The scheme of the refinery wastewater treatment plant and sampling locations are shown in Supporting Information (SI) Figure S1. The wastewater is first treated by physicochemical treatment units including gravity setting, coagulation, walnut shell filtration, and flotation. The hydraulic retention times were $3.5 \mathrm{~h}$ in each physicochemical treatment unit. The primary sludge from the gravity setting and coagulation chambers is pumped into the dewatering room once a month (3-6 ton/month). About onethird of the effluent from walnut shell filtration is reinjected into the oil-producing formations, and the rest of the effluent flows through the flotation unit before entering the activated sludge system. The activated sludge system is composed of anaerobic and aerobic process (A/O process) units, whose hydraulic retention times were 11 and $16 \mathrm{~h}$, respectively. The sludge retention time was about 11-12 days, and the amount of sludge in the activated sludge system was estimated to be 0.2 ton/month in the refinery wastewater treatment plant. After a final secondary clarification step, the effluent of the activated sludge reactor is discharged to the environment.

Occurrences and mass balance of NAs in the treatment plant were explored by analyzing NAs in wastewater, suspended solids, and sludge samples collected from different treatment units in the summer time (May 15, 2013 and May 15, 2014). The refinery processed light crude oil during the sampling periods. Seasonal variations of NAs in the plant were further studied by analyzing NAs in wastewater collected in winter (October 30, 2013). The characteristics of collected wastewater, suspended solids, and sludge samples are given in SI Table S1. For each sampling location, wastewater samples were collected every $3 \mathrm{~h}$, and four samples were mixed as a $12 \mathrm{~h}$ composite water sample. The composite samples were collected twice and analyzed separately for each occasion (May 15-16, 2013, October 30-31, 2013, and May 15-16, 2014). The suspended solids were collected by filtering the water samples, and the glass microfiber filters (Whatman GF/C $1.2 \mu \mathrm{m}$, Maidstone, UK) used for filtering four composite water samples collected in each treatment unit in summer were extracted as one sample for analysis. The dewatered sludge and excess sludge were collected at the outlets of physicochemical treatment chambers and the activated sludge system, respectively, and sludge samples collected in summers were mixed and extracted as one sample for analysis. All water samples were collected in $500 \mathrm{~mL}$ amber glass bottles, which were washed by methanol and purified water before use. Water samples were extracted within $4 \mathrm{~h}$ in the local laboratory after being filtered. Sludge samples were stored at $-20{ }^{\circ} \mathrm{C}$ until analysis. During the sampling period, the wastewater for treatment was around $13000 \mathrm{~m}^{3} / \mathrm{d}$, and the average nitrogen concentrations in the secondary effluent were $0.02 \mathrm{mg} / \mathrm{L}$ for $\mathrm{NO}_{2} \mathrm{~N}$ and 0.009 for $\mathrm{NO}_{3} \mathrm{~N}$. The other treatment parameters in the treatment plant (e.g., $\mathrm{H}_{2} \mathrm{SO}_{4}$, Sulfur Compounds (SCs), Suspend Solids (SS), and petroleum content) were listed in SI Table S2.

Sample Preparation. The chemicals and reagents used in the present study are provided in the SI. The methods for semiquantification of NAs and oxy-NAs in wastewater and sediment samples have been reported previously. ${ }^{34,35}$ Briefly, approximately $250 \mathrm{~mL}$ of wastewaters spiked with $0.1 \mu \mathrm{g}$ of surrogate standards (12-oxochenodeoxycholic acid and 1pyrenebutyric acid) were extracted with MAX cartridge (Oasis MAX, $6 \mathrm{~mL}, 150 \mathrm{mg}$, Waters, USA) which was preconditioned by use of $6 \mathrm{~mL}$ of methanol and $6 \mathrm{~mL}$ of purified water. The cartridges were rinsed with $6 \mathrm{~mL}$ of $5 \%$ ammonia and then dried under a flow of nitrogen. The MAX cartridge was prewashed with $6 \mathrm{~mL}$ of methanol which was discarded and then eluted with $12 \mathrm{~mL}$ of ethyl acetate saturated with hydrochloric acid ( $2 \mathrm{M} \mathrm{HCl}$ :ethyl acetate $=1: 10, \mathrm{v} / \mathrm{v})$. The eluate was washed three times with pure water and reconstituted with $100 \mu \mathrm{L}$ of methanol for analysis by an ultrahigh-pressure liquid chromatography (UPLC) coupled to a quadrupole time-of-flight mass spectrometer (QTOF-MS) with electrospray ionization in negative ionization mode $\left(\mathrm{ESI}^{-}\right)$.

The sludge (about $0.5 \mathrm{~g}$ ) and suspend solid (about $0.1 \mathrm{~g}$ ) samples were first freeze-dried and then were spiked with $5 \mu \mathrm{g}$ of surrogate standards (1-pyrenebutyric acid and 12-oxochenodeoxycholic acid) before Soxhlet extraction with a total of $200 \mathrm{~mL}$ of hexane/MTBE/methanol (1:1:1, v/v) mixture solution for $24 \mathrm{~h}$. The extracts were concentrated to approximately $5 \mathrm{~mL}$ by rotary evaporation and then dried under a gentle stream of nitrogen gas to approximately $3 \mathrm{~mL}$ to 
Table 1. Concentrations of NAs in Wastewater Collected from Different Treatment Units in a Petroleum Refinery Wastewater Treatment Plant, North China $(\mu \mathrm{g} / \mathrm{L})^{a}$

\begin{tabular}{|c|c|c|c|c|c|c|c|}
\hline NAs & PW & GE & $\mathrm{CE}$ & WE & FE & $\mathrm{AE}$ & SE \\
\hline total & $392 \pm 113$ & $289 \pm 26$ & $270 \pm 36$ & $263 \pm 19$ & $349 \pm 17$ & $123 \pm 57$ & $113 \pm 82$ \\
\hline$Z=0$ & $51 \pm 10$ & $30 \pm 1.8$ & $30 \pm 7.1$ & $28 \pm 6.6$ & $32 \pm 14$ & $5.1 \pm 4$ & $6.3 \pm 5.2$ \\
\hline$Z=-2$ & $109 \pm 21$ & $91 \pm 18$ & $86 \pm 5.7$ & $84 \pm 10$ & $111 \pm 18$ & $20 \pm 28$ & $5.8 \pm 1.9$ \\
\hline$Z=-4$ & $109 \pm 31$ & $91 \pm 10$ & $84 \pm 13$ & $82 \pm 7.5$ & $109 \pm 5.8$ & $25 \pm 26$ & $15 \pm 7.1$ \\
\hline$Z=-6$ & $52 \pm 31$ & $35 \pm 13$ & $33 \pm 11$ & $33 \pm 8.3$ & $50 \pm 4.8$ & $22 \pm 8.1$ & $24 \pm 19$ \\
\hline$Z=-8$ & $31 \pm 23$ & $19 \pm 5.8$ & $16 \pm 5.1$ & $16 \pm 3.3$ & $21 \pm 3.5$ & $17 \pm 9.2$ & $20 \pm 17$ \\
\hline$Z=-10$ & $19 \pm 13$ & $11 \pm 3.6$ & $10 \pm 3.2$ & $10 \pm 2.3$ & $13 \pm 3.0$ & $12 \pm 6.1$ & $14 \pm 11$ \\
\hline$Z=-12$ & $13 \pm 11$ & $7.5 \pm 3.2$ & $6.6 \pm 2.8$ & $6.5 \pm 1.9$ & $8.1 \pm 2.6$ & $12 \pm 8.7$ & $16 \pm 13$ \\
\hline$Z=-14$ & $8.9 \pm 8$ & $4.6 \pm 2.2$ & $4.1 \pm 2$ & $4 \pm 1.4$ & $4.7 \pm 2.1$ & $10 \pm 8.6$ & $13 \pm 13$ \\
\hline
\end{tabular}

${ }^{a} \mathrm{PW}$ : petroleum wastewater, GE: gravity settling effluent, $\mathrm{CE}$ : coagulation effluent, WE: walnut shell effluent, FE: flotation effluent, AE: A/O process effluent, SE: secondary effluent.

ensure the complete removal of hexane and MTBE. The residues were dissolved in $30 \mathrm{~mL}$ of water and then purified by the same method of solid-phase extraction for water sample preparation (Oasis MAX cartridges, $6 \mathrm{~mL}, 150 \mathrm{mg}$, Waters, Milford, MA). The elute of cartridge was washed with pure water to reduce the $\mathrm{pH}$ levels toward neutral and reconstituted with $500 \mu \mathrm{L}$ of methanol for UPLC-ESI ${ }^{-}$-QTOF-MS analysis.

Since UPLC-QTOF-MS analysis cannot differentiate aromatic NAs from alicyclic acids, aromatic NAs were isolated and semiquantified using a previously developed method. ${ }^{28}$ Aliquot of elute was derivatized with $\mathrm{BF}_{3}-$ methanol, and separation of aromatic NAs from alicyclic NAs was then achieved by using $6 \mathrm{~mL}$ Discovery Ag-Ion SPE cartridges (750 mg sorbent; Sigma-Aldrich, Dorset, UK). The isolated aromatic NA esters were analyzed by gas chromatographymass spectrometer (GC-MS). Details of sample preparations for aromatic NAs and parameters for instrumental analysis of UPLC-QTOF-MS and GC-MS were provided in the SI.

Extracts of water and suspend solids in wastewater samples collected from different treatment units were combined and redissolved in dimethyl sulfoxide (DMSO) to assess the estrogenic and antiestrogenic activities using the yeast twohybrid assay. ${ }^{36}$ The details of the bioanalysis were provided in the SI.

Quality Assurance and Quality Control (QA/QC). All equipment were rinsed with acetone and hexane to avoid sample contamination, and laboratory blanks were conducted for every batch of samples. In this study, total NAs in field blank samples were determined to be $<10 \mu \mathrm{g}$ in water and $<1.3$ $\mu \mathrm{g}$ in sludge samples. Efficiencies of the sample preparation procedure were assessed by analyzing sludge and wastewater samples collected from each treatment units spiked with standard solutions of model NAs and oxy-NAs. The absolute recoveries of model NA and oxy-NA compounds in triplicate spiked samples were $80 \pm 17 \%$, $84 \pm 16 \%$, $80 \pm 15 \%$, $83 \pm$ $19 \%, 87 \pm 17 \%, 89 \pm 17 \%$, and $89 \pm 18 \%$ in petroleum wastewater, gravity setting effluent, coagulation effluent, walnut shell effluent, flotation effluent, A/O effluent, and secondary effluent, respectively, and $71 \pm 19 \%$ for sludge samples. Currently, concentrations of NA mixtures were generally semiquantified based on integration of the hump peak of each NA congener assuming that the responses for individual compounds in the hump peaks were similar, ${ }^{12,37-41}$ since the separation method and standards for all the individual NAs were not available. While the commercial NAs and oil field NAs may contain NA congeners with different structures and response factors, ${ }^{42}$ semiquantification of the analytes was achieved using an internal standard method with calibration against standard solutions of commercial NAs (Acros) reported previously. ${ }^{5,25,34}$ NAs and oxy-NAs were semiquantified in sample extracts relative to 1-pyrenebutyric acid and 12oxochenodeoxycholic acid, respectively. Surrogate standards were spiked to samples prior to extraction to compensate for the loss of target compounds during the extraction process and correct the variation of instrument response and matrix effect, although the response variability would still occur in the analysis. Recoveries of 1-pyrenebutyric acid and 12-oxochenodeoxycholic acid were $76 \pm 12 \%$ and $70 \pm 11 \%$ in all water samples and $74 \pm 14 \%$ and $71 \pm 17 \%$ in all suspended solid samples. The method detection limits (MDL) were based on the peak-to-peak noise of the baseline near the analyte peak obtained by analyzing field samples and on a minimum value of 3 for signal-to-noise for model NA and oxy-NA compounds. The MDLs of the model compounds ranged from 0.7 to $15 \mathrm{ng} /$ $\mathrm{L}$ in wastewater samples and from 0.1 to $1.0 \mathrm{ng} \mathrm{g}^{-1} \mathrm{dw}$ in suspended solid samples. Mass ions of 119 and 105 were selected for semiquantification of aromatic NAs relative to the surrogate (1-pyrenebutyric acid), ${ }^{26}$ and percentages of aromatic NAs in total NAs were estimated assuming that the responses for NAs and aromatic NAs were similar to that of 1pyrenebutyric acid in UPLC-QTOF-MS and GC-MS analysis, respectively. The data analysis including the calculation of mass flow, solid-water partition coefficient $\left(K_{\mathrm{d}}, \mathrm{L} / \mathrm{kg}\right)$, and contribution of sorption and degradation to the removal of NAs in the plant is provided in the SI.

\section{RESULTS AND DISCUSSION}

Occurrence. Table 1 shows the concentrations of total NAs (including both alicyclic and aromatic NAs) in wastewater samples collected from various treatment units in a petroleum refinery wastewater plant. Concentration of total NAs was 392 $\pm 113 \mu \mathrm{g} / \mathrm{L}$ in the crude petroleum wastewater, and the percentage of aromatic NAs in total NAs was estimated to be $6.0 \%$, suggesting that most NAs $(>90 \%)$ detected in the treatment plant were alicyclic NAs. The relative composition of NA mixtures compared to the sum of all ions observed in the negative-ion ESI full scan mass spectra was $70 \pm 12 \%$ in the crude petroleum wastewater, suggesting that NA mixtures were dominant contaminants in the wastewater. Concentrations of total NAs in the crude petroleum wastewater in the present study were much lower than those in petroleum wastewaters $(4.5-16.6 \mathrm{mg} / \mathrm{L})$ from six United States refineries, ${ }^{25}$ of which concentrations of NAs were semiquantified with the same method, and the possible reason could be the different type of 

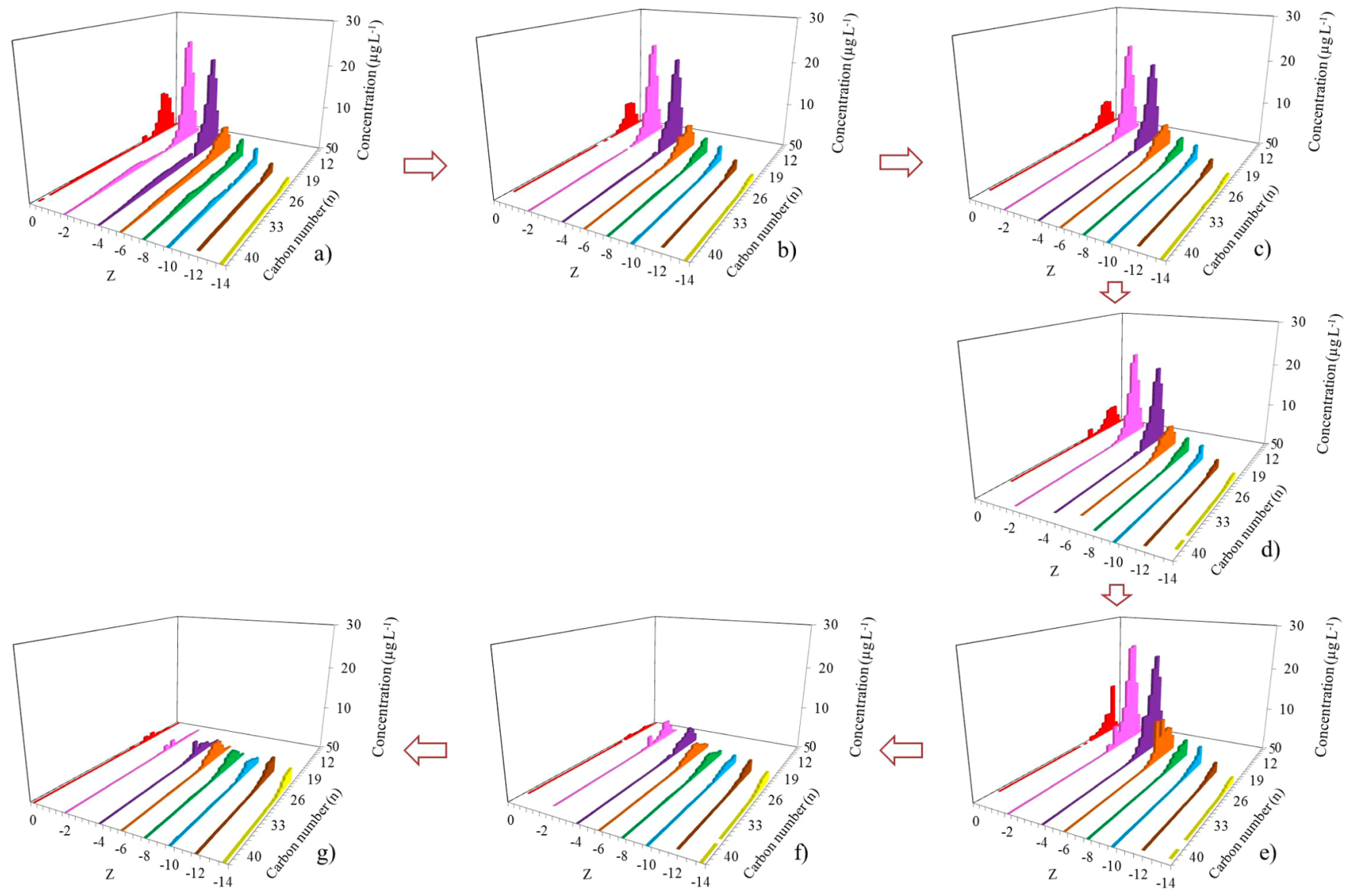

Figure 1. Profiles of NAs in wastewater samples collected from different treatment units in a petroleum refinery wastewater treatment plant, north China: a) petroleum wastewater, b) gravity settling effluent, c) coagulation effluent, d) walnut shell effluent, e) flotation effluent, f) A/O process effluent, and g) secondary effluent.

crude oils. The dominant ions in the crude oil refinery wastewater in the present study were for $Z=-2$ and $Z=-4$ series, accounting for $55.6 \%$ of the total concentrations, followed by $Z=-6$ (13.3\%), $Z=0$ (13.0\%), $Z=-8$ (7.9\%), $Z=-10$ (4.8\%), $Z=-12$ (3.3\%), and $Z=-14$ (2.3\%), which all centered around $n=10-20$ (Figure 1a). The profile with a high abundance of one-three ring NAs with 10-20 carbons in crude oil wastewater were similar to that of crude oil total extractable NA extract in six United States refineries, with the dominant ions of $Z=-2, Z=-4$, and $Z=-6$ and $n$ of $10-$ $20,{ }^{25}$ except for that the proportions of high molecular weight NAs $(n=25-35)$ were relatively high in the present study.

Concentrations of total NAs in physicochemical treatment units were $289 \pm 26 \mu \mathrm{g} / \mathrm{L}, 270 \pm 36 \mu \mathrm{g} / \mathrm{L}, 263 \pm 19 \mu \mathrm{g} / \mathrm{L}$, and $349 \pm 17 \mu \mathrm{g} / \mathrm{L}$ in the effluent of gravity setting, coagulation, walnut shell, and flotation, respectively. About $26.3 \%$ of total NAs were removed after the treatment by gravity setting, and concentrations of total NAs only decreased by $2.2-6.6 \%$ due to the treatment of coagulation and walnut shell units, suggesting that adsorptions in the gravity setting unit would slightly help the initial removal of total NAs in the wastewater. The profiles of total NAs were very constant in wastewater from the physicochemical treatment units, with the dominant ions of $Z=$ $-2(32 \%), Z=-4(31 \%)$, and $Z=-8(12 \%)$ and carbon numbers centered around $n=10-20$ (Figure $1 \mathrm{~b}, \mathrm{c}, \mathrm{d}$, and e). The profiles are differentiated from that of crude oil wastewater by the extreme low percentage of NAs with high carbon numbers $(n=25-35)$, which have been removed by the gravity settling unit. The removal efficiencies of different NA congeners by gravity setting increased linearly from 16.4 to $47.9 \%$ with the $Z$ value decreasing from -2 to -14 (most alicyclic NAs, $>90 \%$ ), indicating that high cyclization NAs could be relatively easily removed by adsorption during the gravity setting processes.

Concentrations of total NAs in effluent of the activated sludge system were $123 \pm 57 \mu \mathrm{g} / \mathrm{L}$, and the removal efficiencies for the total NAs by the $\mathrm{A} / \mathrm{O}$ process were $65 \pm 16 \%$, suggesting that the $\mathrm{A} / \mathrm{O}$ process treatment could effectively remove most NAs in the treatment plant. The removal efficiencies of different NA congeners by the A/O process treatment increased linearly with an increase of the $Z$ value. This indicated that low cyclization NAs are relatively easily removed in the activated sludge system, resulting in the relatively high proportions $(8.1-13.8 \%)$ of high cyclization NAs $(Z=-14-8)$ in the effluent of the activated sludge system (Figure 1f).

Concentrations and profiles of NAs detected in the suspended solids and sludge samples in the treatment plant are given in SI Table S3, Figure S2, and Figure S3. The total concentrations of NAs were $860-2772 \mathrm{mg} / \mathrm{kg}$ in suspended solids from all the treatment units and $1594-2489 \mathrm{mg} / \mathrm{kg}$ in sludge samples from gravity setting and $\mathrm{A} / \mathrm{O}$ treatment units, of which the low variation of the concentrations suggested the constant deposit of NAs in the suspended solids and sludge (SI Table S3). The profiles with dominant ions of $Z=-8-2$ were found for all the solid and sludge samples, but the carbon 
numbers centered around 20-33 in sludge were different from those in suspended solids, in which NAs with high molecular weight and carbon number (33-40) were generally detected with relatively high abundance (SI Figures S2 and S3). The solid-water partition coefficients $\left(K_{\mathrm{d}}, \mathrm{L} / \mathrm{kg}\right)$ for different classes of NA congeners were further calculated, and $K_{\mathrm{d}}$ of total NAs was in the range of 2194-12715 in all the treatment units (Table 2). It is interesting to note that $K_{\mathrm{d}}$ decreased with the $Z$

Table 2. Solid-Water Partition Coefficients $\left(K_{d}, L / k g\right)$ for Different Classes of NA Congeners in the Wastewater Treatment Plant $(\mathrm{L} / \mathrm{kg})^{a}$

\begin{tabular}{lrrrrrr}
\multicolumn{1}{c}{ NAs } & PW & \multicolumn{1}{c}{ GE } & CE & WE & \multicolumn{1}{c}{ FE } & \multicolumn{1}{c}{ AE } \\
total & 2194 & 5952 & 6222 & 4863 & 7943 & 12715 \\
$Z=0$ & 608 & 3200 & 3133 & 3607 & 8156 & 21765 \\
$Z=-2$ & 789 & 2121 & 2116 & 2036 & 5378 & 7300 \\
$Z=-4$ & 1734 & 4385 & 4298 & 3244 & 5450 & 9440 \\
$Z=-6$ & 3538 & 10600 & 10606 & 7394 & 9080 & 13591 \\
$Z=-8$ & 4484 & 13632 & 17188 & 12313 & 17143 & 20941 \\
$Z=-10$ & 4789 & 15909 & 18000 & 14000 & 18231 & 18500 \\
$Z=-12$ & 6077 & 17333 & 20303 & 14769 & 19630 & 9000 \\
$Z=-14$ & 6854 & 21304 & 25610 & 16000 & 23404 & 8600
\end{tabular}

${ }^{a} \mathrm{PW}$ : petroleum wastewater, GE: gravity settling effluent, CE: coagulation effluent, WE: walnut shell effluent, FE: flotation effluent, AE: A/O process effluent.

value of NAs (most alicyclic NAs, >90\%) in all the physicochemical treatment units, but this phenomenon disappeared in the $\mathrm{A} / \mathrm{O}$ process unit. The results indicate that high cyclization NAs were relatively easy to remove by adsorption, which is consistent with the positive correlation between the removal efficiencies and cyclization of NAs in the gravity settling unit, and the sorption behaviors were greatly affected in the $\mathrm{A} / \mathrm{O}$ process.

The total NA concentrations $(113 \pm 82 \mu \mathrm{g} / \mathrm{L})$ for secondary effluent were similar to those in effluent of the activated sludge system, and the removal efficiencies, calculated by comparing concentrations in the raw sewage and secondary effluent, were $73 \pm 17 \%$ for total NAs. A recent study reported occurrences of NAs in oil refinery activated sludge wastewater treatment systems in six United States refineries, but the different type of crude oil hampered a direct comparison of NAs for the same refinery. ${ }^{25}$ The present study found relatively high removal efficiencies of NAs in a refinery wastewater treatment plant, and the removal efficiencies of different NA congeners decreased linearly with the increased cyclization of NAs, which is similar to the structure-persistence relationship of NAs in the A/O process and different from the adsorption behaviors of NA congeners, possibly suggesting the relatively high contribution of the activated sludge system to the removal of NAs in the treatment plant.

Mass Flow and Mass Balance. Mass flows and mass balance of total NAs were determined to assess their potential removal mechanisms in a petroleum refinery wastewater treatment plant (Figure 2 and SI Table S4). In petroleum wastewater, the combined aqueous and solid phase mass flows of total NAs were about $7725 \pm 1471 \mathrm{~g} / \mathrm{d}$, and mass flows entering the wastewater treatment plant were $5097 \mathrm{~g} / \mathrm{d}$ and $2628 \mathrm{~g} / \mathrm{d}$ in the water-phase and sorbed fraction, respectively. The proportion of total NAs sorbed on particles was 34\% of that in the water-phase, suggesting that NAs were discharged to the environment mainly in aqueous phase although these compounds have high values of $K_{d}$ (Table 2). In the physicochemical treatment units, mass change percentages ranged from 5.3 to $10.6 \%$ in coagulating, walnut shell, and flotation treatment units. The low mass change percentage and variability in the treatment units indicated that adsorption was of minor importance in the removal of total NAs in the plant. Total NAs mass flow entering the activated sludge system was about $4536 \pm 150 \mathrm{~g} / \mathrm{d}$, and the great mass reduction percentage was observed in both the water-phase $(64.8 \%)$ and sorbed fraction $(65.7 \%)$ in the treatment unit. The high mass reduction in the activated sludge system suggested that the A/O process greatly contributed to the removal of NAs. For filtered secondary effluents, the mass flow was about $1016 \pm$ $735 \mathrm{~g} / \mathrm{d}$, and the sorbed amount was ignored due to the low concentrations of suspended solids in the effluent. The total NAs mass in the dewatered and excess sludge was 498 and 9.6 $\mathrm{g} / \mathrm{d}$, respectively.

To assess the contribution of sorption and degradation to the removal of total NAs in the plant, the mass balance of NAs in the wastewater treatment plant was expressed in chemical mass fractions (\%) detected in (i) secondary effluent, (ii) dewatered and excess sludge, and (iii) total lost, relative to the calculated

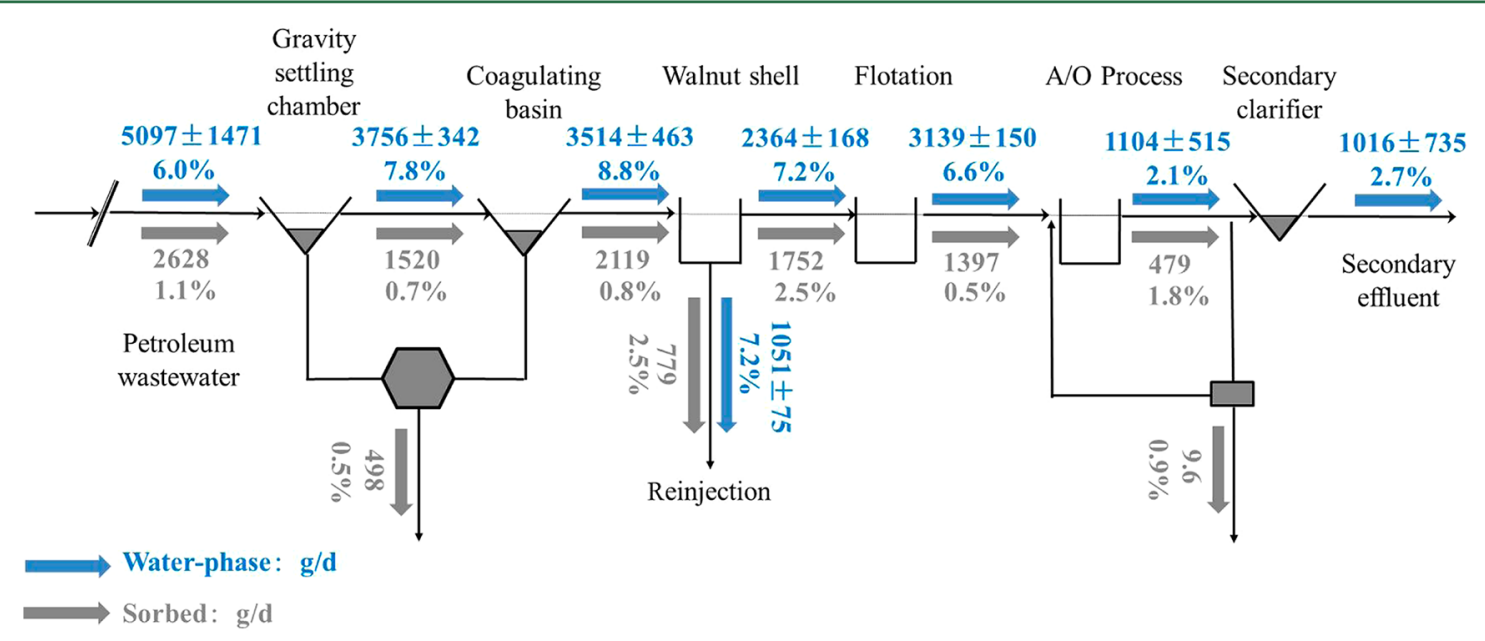

Figure 2. Mass flows $(\mathrm{g} / \mathrm{d})$ of total NAs and percentages of aromatic NAs in total NAs (\%) in a petroleum refinery wastewater treatment plant, north China. 


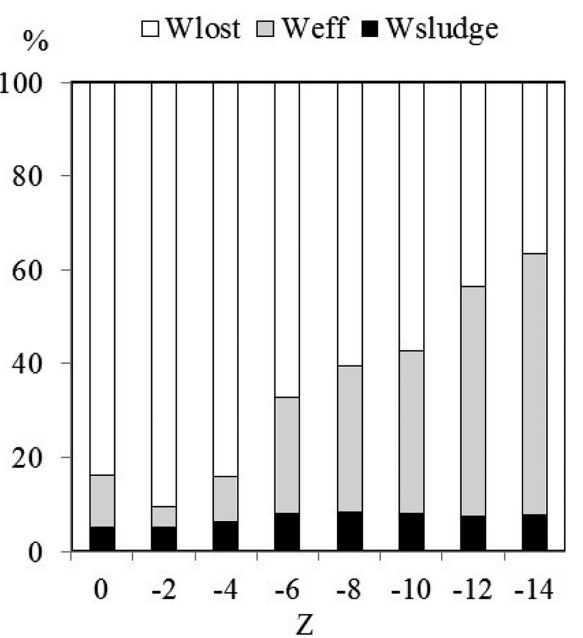

Figure 3. Mass proportions of NAs in (i) secondary effluent (Weff), (ii) dewatered sludge (Wsludge), and (iii) total lost (Wlost) relative to the calculated initial loading $(100 \%)$ in the petroleum refinery wastewater treatment plant.

initial loading (100\%) (Figure 3). The calculated fraction of mass losses due to degradation for total NAs accounted for $74.4 \%$ of initial loadings, while the contribution of sorption and output of sludge was much less $(6.6 \%)$. The mass proportion of total lost for different NA congeners increased linearly from 36 to $90 \%$ with increasing of $Z$ values, which is consistent with the fact that NAs with increased cyclicity are more recalcitrant than lower cyclization NA during the biodegradation processes $^{5,10,13,14}$ (Figure 3). The results demonstrated that biodegradation via activated sludge treatment system was the major removal mechanism of NAs in the plant.

Mass flows and mass balance of aromatic NAs were further determined since the aromatic acids might represent a toxic and/or recalcitrant fraction of NA mixtures. As shown in Figure 2, mass flows of aromatic NAs entering the wastewater treatment plant were $306 \mathrm{~g} / \mathrm{d}$ and $29 \mathrm{~g} / \mathrm{d}$ in the water-phase and sorbed fraction, respectively. In the physicochemical treatment units, the percentage of aromatic NAs in total NAs were constant in wastewater $(6.0-8.8 \%)$, and mass flows of aromatic NAs were in the range of 246-309 g/d (Figure 2). The mass flow of aromatic NAs entering the activated sludge system was about $306 \mathrm{~g} / \mathrm{d}$, and great mass reduction (92\%) was observed in water-phase. Similar high mass reduction in the A/ O treatment unit (97\%) was also found for individual aromatic NAs $\left(\mathrm{C}_{11} \mathrm{H}_{16} \mathrm{O}_{2}\right.$, selected ions: $\left.133,105,77^{26}\right)$, of which mass flows were shown in SI Figure S4. In the mass balance analysis, the fraction of mass losses due to degradation for aromatic NAs accounted for $87.4 \%$ of initial loadings, and the contribution of sorption and output of sludge was only $0.78 \%$. The results demonstrated that aromatic NAs, similar to total NAs, can be greatly removed by biodegradation in the $\mathrm{A} / \mathrm{O}$ treatment unit. This conclusion is consistent with the results of microbial biodegradation of individual aromatic alkanoic NAs. ${ }^{30,33}$ Furthermore, estrogenic activities in wastewater from different treatment units were determined, since the aromatic NA fraction was reported to have an estrogenic effect. ${ }^{31,32}$ Estrogenic activities were not observed in the sample extracts possibly due to the low concentrations of NA mixtures, but antiestrogenic activities were found in wastewater from physicochemical treatment units with ER antagonist potency ranging from 750 to $2100 \mathrm{ng}$ Tamoxifen/L (Figure 4 and SI

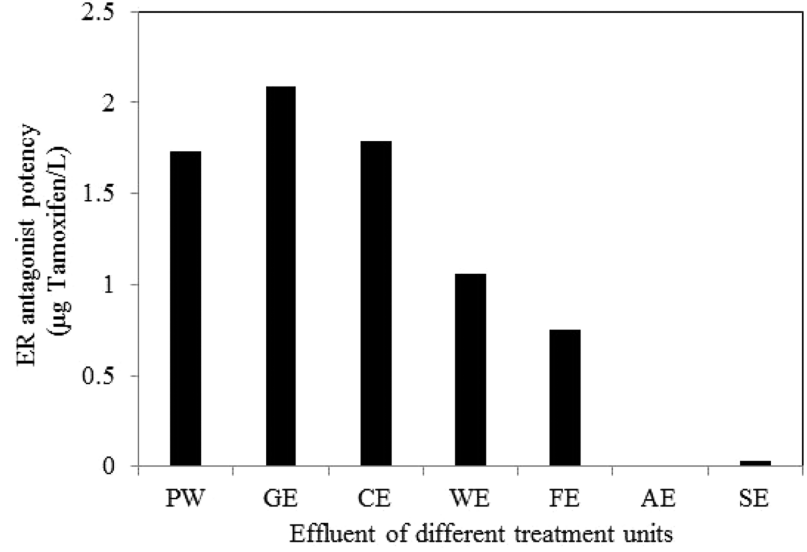

Figure 4. Antiestrogenic activities (ng Tamoxifen/L) in wastewater samples collected from different treatment units in a petroleum refinery wastewater treatment plant, north China. PW: petroleum wastewater, GE: gravity settling effluent, $\mathrm{CE}$ : coagulation effluent, WE: walnut shell effluent, FE: flotation effluent, AE: A/O process effluent.

Figure S5). It should be noted that the antiestrogenic activities disappeared in the $\mathrm{A} / \mathrm{O}$ process effluent and secondary effluent, suggesting the effective removal of the toxic compounds by the activated sludge system (Figure 4). The results further confirmed that biodegradation was the major mechanism for removing alicyclic NAs, aromatic NAs, and related toxicities in the plant.

It is interesting to note that the NAs with low $Z$ values (most alicyclic NAs, >90\%) were relatively recalcitrant to biodegradation (Figure 3), which is a complete contrast to the preferential adsorption of NAs with less negative Z. Previous studies have tested various types of adsorption materials in a laboratory to help remove the persistent fraction of NAs. ${ }^{21-24}$ Thus, employing an efficient adsorbent together with biodegradation processes within the integrated activated sludge treatment plant would help to cost-effectively and efficiently remove most NAs including toxic and recalcitrant fractions in wastewater to meet the no-discharge policy for the compounds.

Seasonal Differences. Concerning the possible seasonal difference in the removal efficiencies of NAs, seasonal variations in concentrations of total NAs in the PRWW were investigated. Concentrations of total NAs were $337 \pm 17,312 \pm 30,293 \pm$ 9.4, $234 \pm 7.0,248 \pm 30,219 \pm 16$, and $159 \pm 58 \mu \mathrm{g} / \mathrm{L}$ in petroleum wastewater, gravity settling effluent, coagulation effluent, walnut shell effluent, flotation effluent, $\mathrm{A} / \mathrm{O}$ process effluent, and secondary effluent, respectively, in winter. While the concentration and profile of NAs were similar in the two seasons, the removal efficiencies of total concentrations of NAs in winter $(53 \pm 15 \%)$ were relatively low compared with those in summer $(73 \pm 17 \%)$ (Figure 5a, $p=0.228, t$ test), and the negative average removal efficiencies for $Z=-12$ and -14 in summer were observed possibly due to the wide variations among four times of sampling. The removal efficiencies of NAs in the physicochemical treatment units, calculated by comparing concentrations in petroleum wastewater and flotation effluent, were both relatively low in summer and winter $(<30 \%)$, which is consistent with the low contribution of physicochemical treatment to the removal of NAs in the plant; and the removal efficiencies of the activated sludge system in winter $(11 \pm 17 \%)$ was significantly lower than those in summer $(65 \pm 16 \%)(p<0.05, t$ test $)$, suggesting that the activated sludge units are more effective in decreasing the NA 

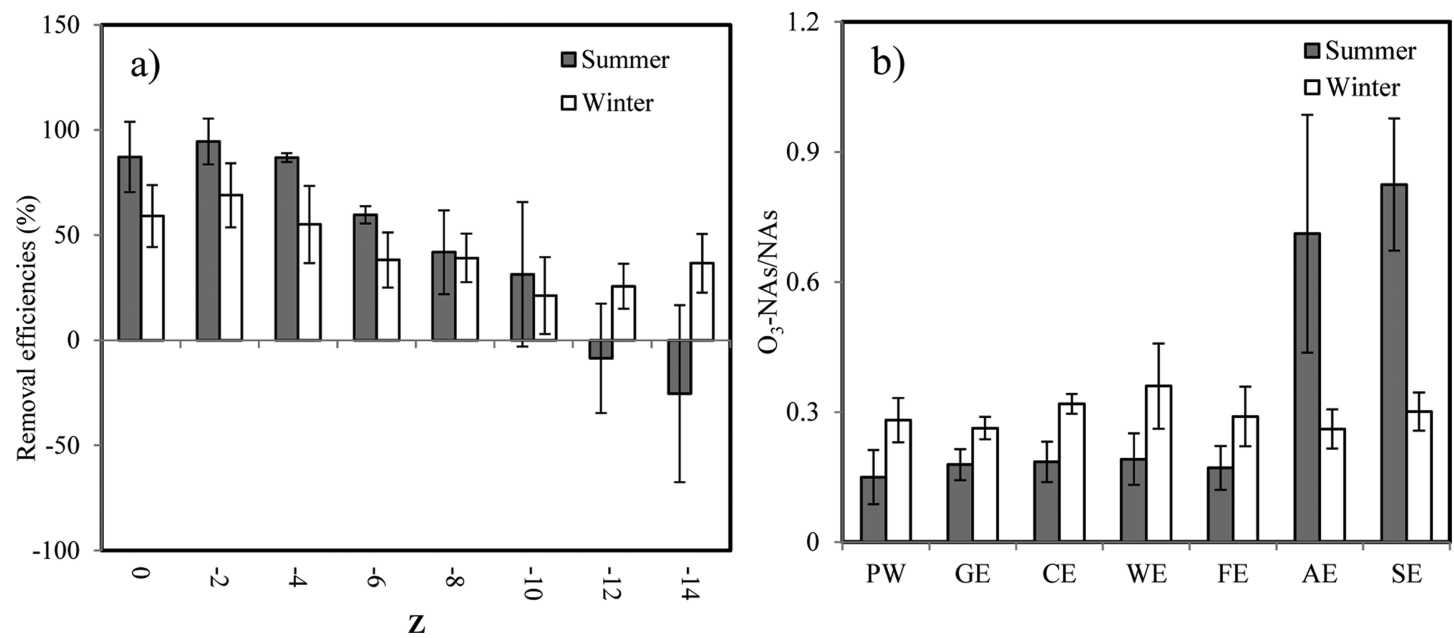

Figure 5. (a) Seasonal variations of removal efficiencies (\%) and (b) oxidation efficiencies $\left(\mathrm{O}_{3}-\mathrm{NAs} / \mathrm{NAs}\right)$ of NAs in the petroleum refinery wastewater plant. PW: petroleum wastewater, GE: gravity settling effluent, CE: coagulation effluent, WE: walnut shell effluent, FE: flotation effluent, AE: A/O process effluent, SE: secondary effluent.

concentrations in the summer time and temperature would affect the removal efficiencies during the treatment.

Oxy-NAs, considered as a potential marker for the degradation of NAs in aquatic samples, were observed during aerobic microbial biodegradation of commercial NAs. ${ }^{10,34,35,37,43,44}$ Concentration ratios between oxy-NAs and NAs has been successfully applied to the assessment of weathering characteristics of NAs in the oil spilled area. ${ }^{10,35}$ Thus, the concentration ratios $\left(\mathrm{O}_{3}-\mathrm{NAs} / \mathrm{NAs}\right)$ were used to assess the biodegradation of NAs in the petroleum refinery wastewater plant. In winter, the concentration ratios were similar in different treatment units with values ranging from 0.26 to 0.36 (Figure $5 b$ ). However, the concentration ratios in summer remained constant in physicochemical treatment units (0.15-0.19) and shift to $0.71-0.82$ after the active sludge system (Figure $5 \mathrm{~b}$ ), suggesting the high microbial biotransformation activities of the $\mathrm{A} / \mathrm{O}$ processes in summer, which is consistent with the high removal efficiencies in the treatment unit. The results confirmed that biodegradation via activated sludge was the major process contributing to the removal of most NAs including toxic and recalcitrant fractions, and the temperature would greatly influence the treatment efficiencies.

Overall, the present study reported for the first time the mass balance of total NAs and aromatic NAs in a petroleum refinery wastewater plant. The high cyclization NAs were relatively easily subject to adsorption, which slightly helps the initial removal of NAs in the wastewater. The distribution of mass fractions of NAs in the plant indicated that biodegradation was the major removal mechanism of NAs (including alicyclic NAs, aromatic NAs, and related toxicities) in the activated sludge system, and the removal efficiencies by the processes was largely affected by temperature. The results of the investigations indicated that employing an efficient adsorbent together with optimized biodegradation processes would help cost-effectively and efficiently remove NA mixtures in wastewater to meet the no-discharge policy for the pollutants.

\section{ASSOCIATED CONTENT}

\section{S Supporting Information}

Text, figures, and tables addressing (1) chemicals and reagents and instrument analysis; (2) analysis of aromatic NAs; (3) assay of agonist and antagonist; (4) calculations of mass flow, mass proportions, and solid-water partition coefficients; (5) characteristics of collected wastewater, suspended solids, and sludge samples; (6) treatment parameters in the petroleum refinery wastewater treatment plant; (7) concentrations of NAs $(\mathrm{mg} / \mathrm{kg})$ in suspended solids and sludge samples; (8) mass flux $(\mathrm{g} / \mathrm{d})$ of NAs in the petroleum refinery wastewater treatment plant; (9) sample locations in the plant; (10) profiles of NAs in suspended solids, activated sludge, and dewatered sludge; (11) mass flows $(\mathrm{g} / \mathrm{d})$ of individual aromatic NAs $\left(\mathrm{C}_{11} \mathrm{H}_{16} \mathrm{O}_{2}\right)$; and (12) dose-response curves of antiestrogen activities in sample extracts. This material is available free of charge via the Internet at http://pubs.acs.org.

\section{AUTHOR INFORMATION}

\section{Corresponding Author}

*Phone/Fax: 86-10-62759126. E-mail: wany@urban.pku.edu. cn. Corresponding author address: College of Urban and Environmental Sciences, Peking University, Beijing 100871, China.

\section{Notes}

The authors declare no competing financial interest.

\section{ACKNOWLEDGMENTS}

The research is supported by National Natural Science Foundation of China $(21177003,21422701)$ and State High Technology Research and Development (863) Project of China (2012AA063401).

\section{REFERENCES}

(1) Botalova, O.; Schwarzbauer, J.; Frauenrath, T.; Dsikowitzky, L. Identification and chemical characterization of specific organic constituents of petrochemical effluents. Water Res. 2009, 43, 37973812.

(2) Coelho, A.; Castro, A. V.; Dezotti, M.; Sant'Anna, J. G. L. Treatment of petroleum refinery sourwater by advanced oxidation processes. J. Hazard. Mater. 2006, 137, 178-184.

(3) Clemente, J. S.; Fedorak, P. M. A review of the occurrence, analyses, toxicity, and biodegradation of naphthenic acids. Chemosphere 2005, 60, 585-600.

(4) Frank, R. A.; Fischer, K.; Kavanagh, R.; Burnison, B. K.; Aresenault, G.; Headley, J. V.; Peru, K. M.; van der Kraak, G.; Solomon, K. R. Effect of carboxylic acid content on the acute toxicity of oil sands naphthenic acids. Environ. Sci. Technol. 2009, 43, 266-271. 
(5) Misiti, T. M.; Tezel, U.; Tandukar, M.; Pavlostathis, S. G. Aerobic biotransformation potential of a commercial mixture of naphthenic acids. Water Res. 2013, 47, 5520-5534.

(6) Rogers, V. V.; Wickstrom, M.; Liber, K.; MacKinnon, M. D. Acute and subchronic mammalian toxicity of naphthenic acids from oil sands tailings. Toxicol. Sci. 2002, 66, 347-355.

(7) Kannel, P. R.; Gan, T. Y. Naphthenic acids degradation and toxicity mitigation in tailing wastewater systems and aquatic environments: A review. J. Environ. Sci. Health, Part A: Toxic/Hazard. Subst. Environ. Eng. 2012, 47, 1-21.

(8) Yang, M.; Zeng, S. K. Pollutant removal-oriented yeast biomass production from high-organic-strength industrial wastewater: A review. Biomass Bioenergy 2014, 64, 356-362.

(9) Johnson, R. J.; West, C. E.; Swaih, A. M.; Folwell, B. D.; Smith, B. E.; Rowland, S. J.; Whitby, C. Aerobic biotransformation of alkyl branched aromatic alkanoic naphthenic acids via two different pathways by a new isolate of Mycobacterium. Environ. Microbiol 2012, 14, 872-882.

(10) Han, X. M.; Mackinnon, M. D.; Martin, J. W. Estimating the in situ biodegradation of naphthenic acids in oil sands process waters by HPLC/HRMS. Chemosphere 2009, 76, 63-70.

(11) Afzal, A.; Drzewicz, P.; Pérez-Estrada, L. A.; Chen, Y.; Martin, J. W.; Gamal El-Din, M. Effect of molecular structure on the relative reactivity of naphthenic acids in the $\mathrm{UV} / \mathrm{H}_{2} \mathrm{O}_{2}$ advanced oxidation process. Environ. Sci. Technol. 2012, 46, 10727-10734.

(12) Holowenko, F. M.; Mackinnon, M. D.; Fedorak, P. M. Characterization of naphthenic acids in oil sands waste waters by gas chromatography-mass spectrometry. Water Res. 2002, 36, 28432855.

(13) Clemente, J. S.; MacKinnon, M. D.; Fedorak, P. M. Aerobic biodegradation of two commercial naphthenic acids preparations. Environ. Sci. Technol. 2004, 38, 1009-1016.

(14) Han, X. M.; Scott, A. C.; Fedorak, P. M.; Bataineh, M.; Martin, J. $\mathrm{W}$. Influence of molecular structure on the biodegradability of naphthenic acids. Environ. Sci. Technol. 2008, 42, 1290-1295.

(15) Peng, H.; Volchek, K.; MacKinnon, M.; Wong, W. P.; Brown, C. W. Application of nanofiltration to water management options for oil sands operations. Desalination 2004, 170, 137-150.

(16) Kim, E. S.; Liu, Y.; El-Din, M. G. Evaluation of membrane fouling for in-line filtration of oil sands process-affected water: the effects of pretreatment conditions. Environ. Sci. Technol. 2012, 46, 2877-2884.

(17) Alpatoa, A.; Kim, E. S.; Dong, S.; Sun, N.; Chelme-Ayala, P.; ElDin, M. G. Treatment of oil sands process-affected water with ceramic ultrafiltration membrane: effects of operation conditions on membrane performance. Sep. Purif. Technol. 2014, 122, 170-182.

(18) Scott, A. C.; Young, R. F.; Fedorak, P. M. Comparison of GCMS and FTIR methods for quantifying naphthenic acids in water samples. Chemosphere 2008, 73, 1258-1264.

(19) El-Din, M. G.; Fu, H. J.; Wang, N.; Chelme-Estrada, L.; PerezEstrada, L.; Drzewicz, P.; Martin, J. W.; Zubot, W.; Smith, D. W. Naphthenic acids speciation and removal during petroleum-coke adsorption and ozonation of oil sands process-affected water. Sci. Total Environ. 2011, 409, 5119-5125.

(20) Martin, J. W.; Barri, T.; Han, X. M.; Fedorak, P. M.; H, M. G.; Perez, L.; Scott, A. C.; Jiang, J. T. Ozonation of sands process-affected water accelerates microbial bioremediation. Environ. Sci. Technol. 2010, 44, 8350-8356.

(21) Pourrezaei, P.; Drzewicz, P.; Wang, Y. N.; El-Din, M. G.; PerezEstrada, L. A.; Martin, J. W.; Anderson, J.; Wiseman, S.; Liber, K.; Giesy, J. P. The impact of metallic coagulants on the removal of organic compounds from oil sands process-affected water. Environ. Sci. Technol. 2011, 45, 8452-8459.

(22) Mohamed, M. H.; Wilson, L. D.; Headley, J. V.; Peru, K. M. Novel materials for environmental remediation of tailing pond waters containing naphthenic acids. Process Saf. Environ. Prot. 2008, 86, 237243.

(23) De Conto, J. F.; Nascimento, J. D.; de Souza, D. M. B.; da Costa, L. P.; Egues, S. M. D.; Freitas, L. D.; Benvenutii, E. V. Solid phase extraction of petroleum carboxylic acids using a functionalized alumina as stationary phase. J. Sep. Sci. 2012, 35, 1044-1049.

(24) Iranmanesh, S.; Harding, T.; Abedi, J.; Seyedeyn-Azad, F.; Layzell, D. B. Adsorption of naphthenic acids on high surface area activated carbons. J. Environ. Sci. Health, Part A: Toxic/Hazard. Subst. Environ. Eng. 2014, 49, 913-922.

(25) Misiti, T.; Tezel, U.; Pavlostathis, S. G. Fate and effect of naphthenic acids on oil refinery activated sludge wastewater treatment systems. Water Res. 2013, 47, 449-460.

(26) Rowland, S. J.; West, C. E.; Scarlett, A. G.; Jones, D.; Boberek, M.; Pan, L.; Ng, M.; Kwong, L.; Tonkin, A. Monocyclic and monoaromatic naphthenic acids: synthesis and characterization. Environ. Chem. Lett. 2011, 9, 525-533.

(27) Rowland, S. J.; West, C. E.; Jones, D.; Scarlett, A. G.; Frank, R. A.; Hewitt, L. M. Steroidal aromatic 'naphthenic acids' in oil sands process-affected water: Structural comparisons with environmental estrogens. Environ. Sci. Technol. 2011, 45, 9806-9815.

(28) Jones, D.; West, C. E.; Scarlett, A. G.; Frank, R. A.; Rowland, S. $\mathrm{J}$. Isolation and estimation of the 'aromatic' naphthenic acid content of an oil sands process-affected water extract. J. Chromatogr. A 2012, $1247,171-175$.

(29) Headley, J. V.; McMartin, D. W. A Review of the occurrence and fate of naphthenic acids in aquatic environments. J. Environ. Sci. Health 2004, 39, 1989-2010.

(30) Johnson, R. J.; Smith, B. E.; Sutton, P. A.; McGenity, T. J.; Rowland, S. J.; Whitby, C. Microbial biodegradation of aromatic alkanoic naphthenic acids is affected by the degree of alkyl side chain branching. ISME J. 2011, 5, 486-496.

(31) Reinardy, H. C.; Scarlett, A. G.; Henry, T. B.; West, C. E.; Hewitt, L. M.; Frank, R. A.; Rowland, S. J. Aromatic naphthenic acids in oil sands process-affected water, resolved by GCxGC-MS, only weakly induce the gene for vitellogenin production in zebrafish (Danio rerio) larvae. Environ. Sci. Technol. 2013, 47, 6614-6620.

(32) Yue, S. Q.; Ramsay, B. A.; Brown, R. S.; Wang, J. X.; Ramsay, J. A. Identification of estrogenic compounds in oil sands process waters by effect directed analysis. Environ. Sci. Technol. 2015, 49, 570-577.

(33) Johnson, R. J.; West, C. E.; Swaih, A. M.; Folwell, B. D.; Smith, B. E.; Rowland, S. J.; Whitby, C. Aerobic biotransformation of alkyl branched aromatic alkanoic naphthenic acids via two different pathways by a new isolate of Mycobacterium. Environ. Microbiol. 2012, 14, 872-882.

(34) Wang, B. L.; Wan, Y.; Gao, Y. X.; Yang, M.; Hu, J. Y. Determination and Characterization of Oxy-Naphthenic Acids in Oilfield Wastewater. Environ. Sci. Technol. 2013, 47, 9545-9554.

(35) Wan, Y.; Wang, B. L.; Khim, J. S.; Hong, S.; Shim, W. J.; Hu, J. Y. Naphthenic acids in costal sediments after the Hebei spirit oil spill: a potential indicator for oil contamination. Environ. Sci. Technol. 2014, $48,4153-4162$

(36) Hu, J. Y.; Xie, G. H.; Aizawa, T. Products of aqueous chlorination of 4-nonylphenol and their estrogenic activity. Environ. Toxicol. Chem. 2002, 21, 2034-2039.

(37) Grewer, D. M.; Young, R. F.; Whittal, R. M.; Fedorak, P. M. Naphthenic acids and other acid-extractables in water samples from Alberta: what is being measured? Sci. Total Environ. 2010, 408, 59976010.

(38) Bataineh, M.; Scott, A. C.; Fedorak, P. M.; Martin, J. W. Capillary HPLC/QTOF-MS for characterizing complex naphthenic acid mixtures and their microbial transformation. Anal. Chem. 2006, $78,8354-8361$.

(39) Martin, J. W.; Han, X. M.; Peru, K. M.; Headley, J. V. Comparison of high- and low-resolution electrospray ionization mass spectrometry for the analysis of naphthenic acid mixtures in oil sands process water. Rapid Commun. Mass Spectrom. 2008, 22, 1919-1924.

(40) Rudzinski, W. E.; Oehlers, L.; Zhang, Y. Tandem mass spectrometric characterization of commercial naphthenic acids and a Maya crude oil. Energy Fuels 2002, 16, 1178-1185.

(41) Clemente, J. S.; Prasad, N. G. N.; Mackinnon, M. D.; Fedorak, P. M. A statistical comparison of naphthenic acids characterized by gas 
chromatography-mass spectrometry. Chemosphere 2003, 50, 12651274.

(42) West, C. E.; Jones, D.; Scarlett, A. G.; Rowland, S. J. Compositional heterogeneity may limit the usefulness of some commercial naphthenic acids for toxicity assays. Sci. Total Environ. 2011, 409, 4125-4131.

(43) Barrow, M. P.; Headley, J. V.; Peru, K. M.; Derrivk, P. J. Data visualization for the characterization of naphthenic acids within petroleum samples. Energy Fuels 2009, 23, 2592-2599.

(44) Hindle, R.; Noestheden, M.; Peru, K.; Headley, J. Quantitative analysis of naphthenic acids in water by liquid chromatographyaccurate mass time-of-flight mass spectrometry. J. Chromatogr. A 2013, $1286,166-174$. 